\title{
TRANSGRESSÃO DO PARADIGMA DA (MULTI)SERIAÇÃO COMO REFERÊNCIA PARA A CONSTRUÇÃO DA ESCOLA PÚBLICA DO CAMPO
}

\author{
Salomão Antônio Mufarrej Hage*
}

\begin{abstract}
RESUMO: O artigo analisa a realidade das escolas públicas do campo, inserindo suas particularidades nos desafios mais abrangentes que enfrentam os movimentos sociais populares do campo para assegurar o direito à universalização da Educação Básica, com qualidade socialmente referenciada e afirmativa da diversidade sociocultural e territorial que constitui o campo no Brasil. Ele socializa os resultados dos estudos realizados pelo Grupo de Estudo e Pesquisa em Educação do Campo na Amazônia (Geperuaz) sobre a realidade das escolas rurais com turmas multisseriadas, considerando o paradoxo existente entre o abandono e a precarização que caracteriza em grande medida as condições de existência dessas escolas e as ações criativas realizadas pelos professores e estudantes no cotidiano escolar, que desafiam as condiçốes adversas nelas vivenciadas, indicando referências para a transgressão do paradigma seriado urbano de ensino atualmente hegemônico nessas escolas.
\end{abstract}

Palavras-chave: Educação do Campo. Escolas Multisseriadas. Educação Básica. Políticas Educacionais. Qualidade da Educação.

\section{TRANSGRESSION OF THE (MULTI)GRADING PARADIGM AS A REFERENCE FOR THE CONSTRUCTION OF THE RURAL PUBLIC SCHOOL}

ABSTRACT: The article analyzes the reality of rural public schools by including their particularities in the broader challenges facing the popular social movements of rural areas. These social movements seek to ensure the right to universal Basic Education with socially relevant quality and affirmative of the sociocultural and territorial diversity that constitute the rural areas in Brazil. It shares the results of studies carried out by the Group of Study and Research in Rural Education in the Amazon (Geperuaz), that investigates the reality of rural schools with multigrade classes, considering the paradox between disrepair and precariousness that to a large extent characterize the conditions of existence of these schools and the creative actions taken by teachers and students in school

\footnotetext{
* Universidade Federal do Pará, Instituto de Ciências da Educação, Programa de Pós-Graduação em Educação e Programa de Linguagens e Saberes da Amazônia. Grupo de Estudo e Pesquisa em Educação do Campo na Amazônia (Geperuaz). E-mail de contato: salomao_hage@yahoo.com.br
} 
daily life that defy the adverse conditions experienced therein. It indicates references to the transgression of the urban grading teaching paradigm, currently hegemonic in these schools.

Keywords: Rural Education. Multigrade Classes. Basic Schooling. Educational Policy. Quality of Education.

\section{TRANSGRESSION DU PARADIGME DES CLASSES MULTI-NIVEAUX COMME RÉFÉRENCE POUR LA CONSTRUCTION DE L'ÉCOLE PUBLIQUE EN ZONE RURALE}

RESUMÉ: L'article analyse la réalité des écoles publiques en Zone Rurale, en mettant leurs particularités dans les défis le plus englobant face aux mouvements sociaux populaires pour assurer le droit à l'universalisation de l'Éducation Basique, avec de la qualité socialement référenciée et affirmative de la diversité socio-culturelle et territoriale qui constitue la réalité au Brésil. Il socialise les résultats des études réalisées par le Groupe d'Étude et de Recherche en Éducation de Zone Rurale en Amazonie (Geperuaz) sur la réalité des écoles agricoles avec des classes multi-niveaux, en considérant le paradoxe existant entre l'abandon et la précarisation qui caractérise dans une large mesure les conditions d'existence de ces écoles et les actions créatives réalisées par les enseignants et les apprenants dans le quotidien scolaire, qui défient les conditions défavorables vécues intensément, en indiquant des références pour la transgression du paradigme urbain des classes multi-niveaux d'enseignement actuellement hégémonique dans ces écoles.

Mots-clés: Enseignement en zone rurale. Classes multi-niveaux. Éducation Basique. Politiques Scolaires. Qualité de l'Enseignement.

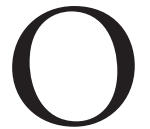

s sujeitos do campo, nesses últimos 15 anos, por meio dos movimentos sociais e sindicais que os representam, têm se mobilizado e organizado um processo nacional de luta para assegurar o direito à educação nas comunidades onde vivem e trabalham, onde produzem e reproduzem sua existência, seus modos de vida e suas formas de pensar e compreender o mundo. Esse processo, que articula as demandas pelo direito a terra com as lutas pelo direito a educação, nacionalmente se reconhece como Movimento de Educação do Campo.

Tendo sua origem nesse processo de luta dos movimentos sociais para resistir à expropriação de terras, a Educação do Campo vincula-se, portanto, à construção de um modelo de desenvolvimento rural que priorize os diversos sujeitos sociais do campo, isto é, que se contraponha ao modelo de desenvolvimento hegemônico que sempre privilegiou os interesses dos grandes proprietários de terra no Brasil, e também se vincula a um projeto maior de educação da classe 
trabalhadora, cujas bases se alicerçam na necessidade da construção de um outro projeto de sociedade e de Nação. (MOLINA 2014; FREITAS, 2011)

A Educação do Campo vincula-se assim, às experiências de luta por um projeto político pedagógico sintonizado com os interesses da classe trabalhadora do campo, na sua diversidade de povos indígenas, povos da floresta, comunidades tradicionais e camponesas, quilombolas, agricultores familiares, assentados, acampados à espera de assentamento, extrativistas, pescadores artesanais, ribeirinhos e trabalhadores assalariados rurais. (FONEC, 2002) Ela teve como ponto de partida o I Encontro Nacional de Educadoras e Educadores da Reforma Agrária - I Enera, realizado em Brasília em 1997, seguido pela realização da I e II Conferência Nacional de Educação do Campo ocorridas, respectivamente, em 1998 e 2004 em Luziânia-Goiás, eventos considerados como marcos fundantes do Movimento de Educação do Campo.

Envolvendo progressivamente um conjunto ampliado de organizaçóes e entidades em encontros locais, regionais e nacionais de Educação do Campo ocorridos desde o final dos anos 1990, esse movimento tem reivindicado que a educação do campo seja assumida como política pública de maneira mais explícita; que os órgãos públicos responsáveis pela educação em nosso país se façam mais presentes e reconheçam a dívida social, cultural e educativa que tem para com os diversos sujeitos que vivem no campo e na floresta; e que seja reconhecida a especificidade desses povos e de suas formas de viver e de ser, de formar-se, de socializar-se, de aprender, de produzir e de relacionar-se com o conhecimento, com as ciências e as tecnologias, com os valores e com a cultura. (CNEC, 2004)

É interessante destacar quanto à legislação que os movimentos sociais - em suas diversas lutas articuladas com as universidades públicas, entidades e organizaçóes da sociedade civil, órgãos do poder público de fomento ao desenvolvimento e da área educacional e instituiçóes internacionais -, têm conquistado um conjunto importante de instrumentos legais que ampliam a definiçáo de marcos regulatórios de reconhecimento da Educação do Campo enquanto política pública, uma condição necessária para que a universalidade do direito à educação se exerça, respeitando as especificidades dos sujeitos do campo, entre os quais destacamos:

- Resolução 1/2002 do CNE/CEB - que estabelece Diretrizes Operacionais para a Educaçáa Básica nas Escolas do Campo;

- Parecer no 1/2006 - que reconhece os Dias Letivos para a aplicaçáo da Pedagogia da Alternância nos Centros Familiares de Formação por Alternância; 
- Resolução 2/2008 do CNE/CEB - que estabelece diretrizes complementares, normas e princípios para o desenvolvimento de políticas públicas de atendimento da Educaçáo Básica do Campo;

- Resolução 4/2010 do CNE/ CEB - que reconhece a Educação do Campo como modalidade específica da Educação Básica e define a identidade da escola do campo;

- Decreto de no 7.352/2010 da Presidência República - que atribui à Educação do Campo a condição potencial de política de Estado e regulamenta o Programa Nacional de Educação na Reforma Agrária (Pronera);

- Portaria 83/2013 do MEC - que institui o Programa Nacional de Educação do Campo - Pronacampo;

- Lei no 12.960/2014 da Presidência República - que estabelece as diretrizes e bases da educação nacional, para fazer constar a exigência de manifestação de órgão normativo do sistema de ensino para o fechamento de escolas do campo, indígenas e quilombolas.

No conteúdo dessas legislações inúmeras questôes são abordadas e incluem dispositivos úteis à luta pelo direito à educação, ao explicitar uma base legal para o Estado implementar novas açôes e programas educacionais para os sujeitos do campo, retomando o debate sobre a universalidade do direito à educaçáo e a necessária observância das singularidades e particularidades nas quais esta se materializa.

Entre as questôes mencionadas, incluem-se: o reconhecimento de que a educação do campo compreende da creche à graduação e a oferta deve ser de responsabilidade compartilhada entre a Uniáo, estados e municípios, de acordo com as diretrizes e metas estabelecidas no Plano Nacional de Educação (Art. $1^{\circ}$; 2010); a afirmação da diversidade que constitui as populaçôes do campo, compreendidas enquanto agricultores familiares, extrativistas, pescadores artesanais, ribeirinhos, assentados e acampados da reforma agrária, trabalhadores rurais assalariados, quilombolas, caiçaras, povos da floresta, caboclos e outros que produzam suas condiçôes materiais de existência a partir do trabalho no meio rural; a importância da escola considerar os aspectos sociais, culturais, ambientais, políticos, econômicos, de gênero, raça e etnia constituintes dessa diversidade ( $\$ 1^{\circ}$. do Art. 1 , 2010); e a determinação de que para receber assistência técnica e as transferências voluntárias de recursos do governo federal, os estados e municípios devem incluir a educação do campo nos seus planos estaduais e municipais de educaçáo.

O protagonismo dos movimentos sociais, fortalecido com a definição dos marcos regulatórios explicitados, também resultou na conquista de programas educacionais destinados aos sujeitos do campo, avançando na garantia do direito 
à educação das populaçóes e sujeitos que vivem no campo. Como exemplos desses programas e açóes destacam-se:

- Programa Projovem Campo Saberes da Terra se destina a escolarização de agricultores de 18 a 29 anos que náo concluíram o ensino fundamental, e pauta em suas ações a formação em nível de pós-graduação latu sensu dos educadores que atuam no Programa;

- Programa de Apoio a Formação Superior em Licenciatura em Educação no Campo (Procampo) oferece graduação a professores das escolas rurais que lecionam nos anos finais do ensino fundamental e no ensino médio;

- Programa de Iniciação à Docência para a Diversidade, no âmbito do Programa Institucional de Bolsa de Iniciação à Docência (Pibid), concede bolsas para alunos regularmente matriculados nos cursos de Licenciatura para Educação do Campo, em parceria com a Capes, visando fortalecer a ação de formação inicial de docentes do campo;

- Programa Escola Ativa anteriormente e, atualmente, Programa Escola da Terra, promovem a formaçáo continuada de professores que atendem as escolas multisseriadas do campo e quilombola, através de um curso de aperfeiçoamento com a utilização da Pedagogia da Alternância;

- Programa Nacional de Educação na Reforma Agrária que oferece educação escolar aos jovens e adultos das famílias beneficiárias dos projetos de assentamento criados ou reconhecidos pelo Incra, em todos os níveis de ensino.

Esses programas têm sido desenvolvidos pelo Ministério da Educação através da articulação entre os órgãos públicos federais, estaduais e municipais, as universidades e as organizaçóes e movimentos sociais populares do campo, e embora enfrentem, em determinadas situaçôes, dificuldades em sua execução, especialmente quanto a quantidade e a morosidade na liberação dos recursos para efetivação das açôes apoiadas eles têm assumido o desafio de pautar as especificidades socioculturais e territoriais nas políticas públicas que chegam até as escolas do campo.

Em março de 2012 o governo federal lançou o Pronacampo, apresentando-o como um conjunto de açóes articuladas de uma "política de educação do campo", para dar materialidade às determinaçóes do decreto presidencial n. 7352/2010, sancionado a partir das mobilizaçóes do Movimento da Educação do Campo, iniciadas, no final da década de 1990. 
De acordo com o MEC, o Pronacampo objetiva oferecer apoio técnico e financeiro aos estados, Distrito Federal e municípios para implementação de uma política nacional de Educaçáo do Campo, capaz de atender às escolas do campo e quilombolas, a partir de quatro eixos de ação: gestão e práticas pedagógicas, formação de professores, educaçáo profissional e tecnológica e infraestrutura. (MEC, 2013)

O Fórum Nacional de Educação do Campo, em seu posicionamento, apresenta críticas ao formato e à lógica de formulação do Pronacampo, indicando que em certa medida, ele encarna historicamente a forma convencional de pensar a política educacional para os trabalhadores do campo em nosso país, distanciando-se das açôes e dos sujeitos que historicamente constituíram a prática social identificada como Educação do Campo; entretanto, reconhece que algumas ações previstas no Programa podem vir a ter impactos significativos nos rumos da Educação do Campo, como por exemplo: Educação Profissional, Construção de Escolas do Campo e Formação de Educadores. (FONEC, 2012)

O novo Plano Nacional de Educação (PNE) recentemente aprovado, Lei $\mathrm{n}^{\circ}$ 13.005, de 25 de Junho de 2014, não apresenta metas explícitas para a Educação do Campo, entretanto, inclui no âmbito de determinadas metas, estratégias que promovem explicitamente o atendimento das populaçôes do campo e das comunidades indígenas e quilombolas, focando as especificidades culturais dessas populaçôes. Entre as metas mencionadas, destacamos: Educação Infantil (Meta.1), Ensino Fundamental de 9 anos (Meta.2), a toda a população de 15 a 17 anos (Meta.3), a população de 4 a 17 anos com deficiência (Meta.4); às crianças em processo de alfabetização (Meta.5), à Educação em Tempo Integral (Meta.6), à Qualidade da Educação Básica (Meta.7), à Educação de Jovens e Adultos (Meta. 10), à Educação Superior (Meta. 12), à elevação da qualidade da educação superior e ampliação da proporção de mestres e doutores do corpo docente (Meta. 13), à Política Nacional de Formação dos Profissionais da Educação (Meta. 15), e à ampliação do investimento público em educação pública (Meta. 20).

Entre as estratégias incluídas nas metas mencionadas, destacamos: limitação à nucleação de escolas e ao deslocamento de crianças, garantindo consulta prévia e informada às comunidades (1.10), desenvolvimento de tecnologias pedagógicas que combinem a organização do tempo e das atividades didáticas entre a escola e o ambiente comunitário (2.16), oferta dos anos iniciais do ensino fundamental nas próprias comunidades (2.10); expansão das matrículas gratuitas de ensino médio integrado à educaçáo profissional (3.7), implantação de salas de recursos multifuncionais e a formação continuada de professores para o atendimento educacional especializado (4.3); apoio à alfabetização de crianças com a produção de materiais didáticos específicos (5.5), oferta de educação em tempo integral com base em consulta prévia e informada (6.7); garantia de transporte gratuito para todos os estudantes visando reduzir a evasão escolar e o tempo médio 
de deslocamento (7.13); desenvolvimento de pesquisas de modelos alternativos de atendimento escolar (7.14); garantia da participação da comunidade na definição do modelo de organização pedagógica e de gestão das instituiçóes; oferta de programa para a formação inicial e continuada de profissionais da educação; e atendimento em educaçáo especial (7.26); desenvolvimento de currículos e propostas pedagógicas, incluindo os conteúdos culturais das comunidades, produzindo e disponibilizando materiais didáticos específicos $(7,27)$; integração da educação de jovens e adultos com a educação profissional (10.3), expansão da Educação Superior incluindo acesso, permanência, conclusão e formação de profissionais para atuação com essas populaçóes (12.13), implementação de açóes para reduzir as desigualdades e favorecer o acesso a programas de mestrado e doutorado (14.5), implementação de programas específicos para formação de profissionais da educação (15.5), articulação do sistema nacional de educação em regime de colaboração, com efetivo cumprimento das funçôes redistributiva e supletiva da União no combate às desigualdades educacionais regionais (20.9).

Ainda que reconheçamos muitos avanços em termos das políticas educacionais para o campo, que se evidenciam na expansão e em mudanças quanto ao atendimento nos diversos níveis de ensino, estamos muito distantes de assegurar a universalização da Educação Básica aos sujeitos do campo, bem como de superar o quadro de acentuada desigualdade educacional, marcado por uma situação ainda precária em relaçáo a permanência e a aprendizagem dos estudantes nas escolas do campo.

Os estudos desenvolvidos, no âmbito do Geperuaz, revelam que do total de 29.830.007 pessoas que vivem no campo em nosso país (IBGE, 2010), somente $21 \%$ acessam a escola, uma vez que existem 6,3 milhóes de matrículas nas escolas do meio rural, segundo o Censo Escolar do Inep (2011).

Em relação as diversas etapas da Educação Básica, os dados do Inep evidenciam com mais precisão essa realidade, uma vez que, nesse mesmo ano, somente $6,98 \%$ das crianças do campo tiveram acesso à creche e apenas $66,80 \%$ conseguiu acesso à pré-escola. No Ensino Fundamental, ainda que a matrícula tenha atingido $91,96 \%$ da populaçáo entre 6 e 14 anos, grande parte desse contingente é atendido nos anos iniciais do Ensino Fundamental, através das escolas multisseriadas, unidocentes, que enfrentam problemas muito sérios relacionados às precárias condiçóes de infraestrutura e funcionamento e quanto a aprendizagem dos alunos. Segundo dados da Coordenação de Educação do Campo do MEC, extraídos do Censo Escolar de 2011, existem atualmente 48.875 escolas multisseriadas no Brasil, as quais representam 56,45\% das Escolas do Campo existentes. Nelas atuam 70 mil docentes e estudam 1,3 milhão de estudantes nos anos iniciais do Ensino Fundamental. 
As estatísticas de atendimento da população rural no Ensino Médio, ao evidenciar um índice de 18,43\% de matrículas nesta etapa escolar, também reforçam a situação de exclusão educacional no país, assim como na Educação de Jovens e Adultos, o atendimento é irrisório no campo, tanto no Ensino Fundamental, quanto no Ensino Médio, ao atingir índices de matrícula de 4,34\% e de $3,10 \%$ respectivamente, conforme os dados do Inep (2011).

Essa realidade também foi retratada nos estudos do Observatório da Equidade - As Desigualdades na Escolarização do Brasil (2009, p. 32) - ao revelarem que para cada duas vagas nos anos iniciais do Ensino Fundamental, existe uma vaga nos anos finais; e para cada seis vagas nos anos finais do Ensino Fundamental, existe apenas uma vaga no Ensino Médio, o que demonstra quão desigual e excludente continua sendo o processo de escolarização em relação aos segmentos empobrecidos e populares do campo em nosso país.

Os desafios também se fazem notar quanto à formação dos professores no campo e precisam ser enfrentados com firmeza, em face da realidade preocupante evidenciada pelo próprio Ministério da Educação, quando se fundamenta nos dados do Censo Escolar do Inep de 2011 e indica que dos 342.845 professores que atuam no campo no Brasil, quase a metade, 160.317, não possui educação superior (46,7\%), e destes, 156.190 possuem o Ensino Médio (97,4\%), e 4.127 possuem apenas o Ensino Fundamental (2,6\%).

Ao associarmos essas deficiências na formação ao fato de que esses educadores desenvolvem o trabalho docente em condiçôes pouco adequadas, onde as escolas possuem infraestrutura precária e funcionam em prédios muito pequenos, em péssimo estado de conservação e, em muitas situaçôes, não possuem nem mesmo prédio próprio e funcionam em salóes de festas, barracóes, igrejas, em um único compartimento onde se realizam as atividades pedagógicas e todas as demais atividades que envolvem os sujeitos da escola e da comunidade; compreendemos com mais clareza os motivos que levam os sujeitos do campo a reivindicarem medidas urgentes e efetivas quanto a implementação de uma política pública de formação de educadores do campo.

De fato, se torna muito difícil desenvolver o trabalho docente de qualidade nas condiçóes inadequadas em que se encontram as escolas rurais na atualidade, e o Censo Escolar de 2011 esclarece com mais detalhes essa situação ao indicar que das 76.229 escolas existentes no campo, 68.651 não acessam internet (90,1\%), 11.413 não possuem energia elétrica (15\%), 7.950 não possuem água potável $(10,4 \%)$, e 11.214 não possuem esgoto sanitário (14,7\%). Essa situação, não estimula professores e estudantes a permanecerem nessas escolas ou sentirem orgulho de estudar nas escolas localizadas em suas próprias comunidades, fortalecendo assim o estigma da escolarização empobrecida e abandonada que tem sido 
ofertada no meio rural, que força as populaçóes do campo a deslocarem-se para estudar na cidade, como solução para essa problemática.

Nesse cenário, marcado pela negação de direitos, pela intensificação do trabalho e pela precarização das condições existenciais de vida e funcionamento das escolas, os movimentos sociais têm denunciado o fechamento das escolas existentes no campo e pautado o Estado e a sociedade brasileira quanto à necessidade de ampliação da oferta de escolarização pública e de qualidade social em todos os níveis no campo.

O Movimento dos Trabalhadores Rurais Sem Terra (MST) lançou, em nível nacional, a campanha Fechar Escola é Crime com o objetivo de denunciar a situação de fechamento das escolas no campo, uma vez que mais de 30 mil escolas foram fechadas entre os anos de 2002 e 2011, conforme estudo que realizamos sobre o Censo Escolar do Inep: em 2002 existiam 107.432 escolas no território rural e, em 2011, o número dessas unidades de ensino reduziu-se para 76.229. O MST busca com essa campanha mobilizar as comunidades rurais, os movimentos sociais, os sindicatos, enfim toda a sociedade, para se indignar e lutar para mudar esta realidade.

Em grande medida, as escolas fechadas no campo, são as multisseriadas, envolvidas em uma complexidade de aspectos que implicam em sua existência e atuação, enquanto forma predominante de atendimento à escolarização dos sujeitos do campo nos anos iniciais do Ensino Fundamental e, de forma menos expressiva, na educação infantil, atendendo os estudantes "encostados" que acompanham seus irmãos mais velhos, assim como, nos anos finais do ensino fundamental e na Educação de Jovens e Adultos.

Essas escolas reúnem estudantes de várias séries e níveis em uma mesma turma, com apenas um professor responsável pela condução do trabalho pedagógico, sendo, portanto, unidocentes e diferenciadas da grande maioria das escolas urbanas, onde os estudantes são enturmados por série e cada turma possui o seu próprio professor.

Essas escolas se constituem geralmente na única alternativa para os sujeitos estudarem nas comunidades rurais em que vivem, encontrando-se expostos a um conjunto de situaçóes que não favorecem o sucesso e a continuidade dos estudos, evidenciando, inclusive, o descumprimento da legislação vigente, que estabelece parâmetros de qualidade a serem alcançados na Educação Básica nas escolas do campo.

$\mathrm{Na}$ sessão seguinte, abordaremos com mais detalhamento as referências que envolvem a realidade das escolas rurais multisseriadas e o processo educativo que nelas se efetiva, buscando compreender a complexidade que configura essa problemática e apresentar possibilidades de intervenção qualificadas diante 
do cenário preocupante que envolve essas escolas e a educação que oferecem às populaçôes do campo.

\section{Precarização, abandono e inovação configuram a realidade das escolas rurais com turmas multisseriadas}

Os estudos que realizamos sobre as escolas públicas do campo, no âmbito do Grupo de Estudos e Pesquisas em Educação do Campo na Amazônia (Geperuaz) e, em especial, sobre as escolas multisseriadas, revelam a identificação de um paradoxo que caracteriza a dinâmica dessas escolas: o quadro dramático de precarizaçáo e abandono em que as escolas se encontram, reflexo do descaso com que tem sido tratada a escolarização obrigatória ofertada as populaçóes do campo; e ao mesmo tempo, as possibilidades construídas por educadores, gestores e sujeitos do campo, no cotidiano das açôes educativas, evidenciando situaçôes criativas e inovadoras que desafiam as condiçóes adversas que configuram a realidade existencial dessas escolas. (HAGE, 2005)

De fato, a realidade da maioria das escolas com turmas multisseriadas revela grandes desafios para que sejam cumpridos os preceitos constitucionais e os marcos legais operacionais anunciados nas legislações específicas, que definem os parâmetros de qualidade do ensino público conquistados com as lutas dos movimentos sociais populares do campo, evidenciando o quadro dramático em que se encontram essas escolas, exigindo uma intervenção urgente e substancial nas condiçóes objetivas e subjetivas de existência dessas escolas.

Esse quadro, em grande medida, é resultante da falta e/ou ineficiência de políticas públicas, em particular da política educacional para o meio rural, situação que envolve fatores macro e microestruturais relacionados, como a profunda desigualdade e exclusão social e o fracasso escolar dos sujeitos do campo, expresso nas taxas elevadas de distorção idade-série, de reprovação e de dificuldades de aprendizagem da leitura e escrita, entre outras situaçôes e fatores que comprometem o ensino e a aprendizagem nas escolas rurais com turmas multisseriadas.

De fato, quando nos interrogamos sobre os fatores que interferem na qualidade da educação e fortalecem o descrédito que se atribui às escolas rurais multisseriadas, em primeira instância se destaca a precariedade dos prédios escolares, as longas distâncias que os estudantes e docentes percorrem no deslocamento até a escola e as condiçóes de transporte inadequadas, a sobrecarga de trabalho docente através de múltiplas funções desempenhadas e a instabilidade no emprego, a falta de acompanhamento das secretarias municipais de educação, a permanência do trabalho infantil, a vulnerabilidade da escola e dos docentes às interferências do poder local, o avanço da política de nucleação vinculada ao transporte escolar e o 
fechamento das escolas, o currículo e os materiais pedagógicos pouco identificados com a realidade do campo... Em fim, múltiplas questóes que impactam na identidade da escola e na organização do trabalho pedagógico, resultando no fracasso escolar dos sujeitos do campo.

Essas particularidades, no conjunto, fortalecem uma visão negativa, pejorativa e depreciativa com relaçáo à escola rural, que leva grande parte dos sujeitos que ensinam, estudam, investigam ou demandam a educação no campo e na cidade, a se referirem às escolas multisseriadas como um "mal necessário", por enxergarem nelas a "única opção de oferta dos anos iniciais do Ensino fundamental nas pequenas comunidades rurais"; e como responsável pelo fracasso escolar dos sujeitos do campo; reforçando com isso, o entendimento "naturalizado" de que a solução para os problemas vivenciados pelas escolas rurais multisseriadas, ocorrerá com sua transformação em escolas seriadas, seguindo o modelo do meio urbano.

Os estudos que realizamos sobre as escolas rurais multisseriadas oportunizaram a compreensão de que para a melhoria da qualidade da educação das escolas do campo será necessário o enfrentamento das mazelas que envolvem as condiçóes de existência dessas escolas, listadas anteriormente, por meio de uma conjugação de açôes que envolvem a articulação entre o macro e o micro, entre questôes estruturais e de concepção, entre questôes de políticas educacionais, de organização do ensino e de formação dos profissionais que atuam nessas escolas.

Nossos estudos também evidenciam que a seriação, que em geral é reivindicada como solução para os graves problemas que permeiam as escolas multisseriadas, já se encontra fortemente presente, materializada nas escolas rurais multisseriadas, de forma precarizada, sob a configuração de multi(série).

Para ser mais explícito, estamos afirmando que as escolas rurais multisseriadas já se constituem enquanto efetivação da seriação no território do campo. Elas representam a maneira possível, viável e exequível que a seriação encontrou para se materializar num contexto próprio como o meio rural, marcado pela precarização da vida, da produção e da educação, conforme indica a visão urbanocêntrica de mundo, que predomina e é hegemônica na sociedade brasileira e mundial.

Em nossos estudos constatamos que é justamente a presença do modelo seriado urbano de ensino nas escolas ou turmas multisseriadas que impede que os professores compreendam sua turma como um único coletivo, com suas diferenças e peculiaridades próprias, pressionando-os para organizarem o trabalho pedagógico de forma fragmentada, levando-os a desenvolver atividades de planejamento, curricular e de avaliação isolados para cada uma das séries, de forma a atender aos requisitos necessários a sua implementação.

A seriação aposta na fragmentação e padronização do tempo, espaço e conhecimento no interior da escola, pré-definindo o ano letivo de duração anual, 
estabelecendo a escola como o local por excelência onde a aprendizagem se efetiva e o conhecimento científico como o que efetivamente tem validade, como legítimo, em detrimento dos saberes dos sujeitos do campo, que são desvalorizados, negados e invisibilizados pela escola.

Essa situação, reveladora da complexidade que configura os desafios que enfrentam os educadores e estudantes das escolas rurais multisseriadas, nos têm demandado apontar possibilidades de intervenção e propostas de solução para essa problemática que sejam contextualizadas, viáveis e que atendam às expectativas do poder público, dos movimentos e organizações sociais, dos órgáos de fomento e, particularmente, dos educadores, pais e estudantes dessas escolas.

As aproximaçóes que temos realizado com a realidade educacional do campo nos ofereceram algumas pistas para referenciar propostas de intervenção nesse quadro dramático e desafiador que envolve as escolas rurais multisseriadas. O eixo central dessas pistas aponta a transgressáo do modelo seriado urbano de ensino como o elemento de convergência dos esforços e energias criadoras, inventivas e de inovaçáo já vivenciados e desenvolvidos pelos gestores, educadores, estudantes, pais e lideranças comunitárias e dos movimentos sociais no cotidiano dessas escolas.

Para ser mais explícito, compreendemos que as mudanças desejadas em relação às escolas rurais multisseriadas, para serem efetivas e provocarem desdobramentos positivos quanto aos resultados do processo de ensino e aprendizagem, devem transgredir a constituição identitária que configura essas escolas, ou seja, devem romper, superar, transcender ao paradigma seriado urbano de ensino, que em sua versão precarizada, se materializa hegemonicamente sob a forma de escolas multi(seriadas).

Em nosso entendimento, essa proposição não se efetivará via decreto, por imposiçấo do poder público, de modo compulsório para todas as escolas ao mesmo tempo, ou mesmo por decisão dos pesquisadores, educadores ou de algum outro segmento escolar isoladamente. Uma mudança dessa natureza, para se materializar e apresentar os resultados significativos deve se constituir paulatinamente, com muito diálogo e reflexão, envolvendo todos os segmentos escolares, com estudos e pesquisas sobre as condiçôes existenciais e as possibilidades de intervenção que atendam às peculiaridades locais das escolas e suas comunidades, aproveitando o acúmulo das experiências e práticas criativas dos sujeitos que participam das escolas rurais multisseriadas, da capacidade inventiva e inovadora desses sujeitos em fazer diferente mesmo quando as condiçóes materiais, objetivas e subjetivas são muito desfavoráveis e as limitações e carências são muito profundas.

Um dos passos importantes na transgressáo do paradigma seriado urbano de ensino se efetiva com a participaçáo coletiva de todos os segmentos escolares na construção do projeto pedagógico, do currículo e na definição das 
estratégias metodológicas e avaliativas a serem efetivados na escola. Quando isso acontece, a escola, ou seja, os diversos segmentos que a constituem, toma para si a responsabilidade de conduzir o planejamento, a gestáo e o processo de ensino e aprendizagem dos estudantes. Essa situação ajuda a corroer alguns dos pilares sobre os quais se assenta o paradigma hegemônico, sua racionalidade e princípios de sociabilidade, ao fortalecer o protagonismo, o empoderamento e a emancipaçáo das escolas e dos sujeitos diante das condiçóes subalternas, clientelistas e patrimonialistas que ainda se manifestam, com muita intensidade, nas relaçóes sociais que se materializam no território do campo.

Neste sentido, construir e implementar as proposições, as políticas e as açóes com os sujeitos do campo envolvidos com as escolas e não para eles, se apresenta como um caminho apropriado para a materialização das mudanças que estamos perseguindo nesse cenário. Isso implica em ouvir os sujeitos do campo e aprender com suas experiências de vida, de trabalho, de convivência e de educação; oportunizá-los o acesso à informação, à ciência e às tecnologias, sem hierarquizar os conhecimentos, valores e ritmos de aprendizagem.

Implica, ainda, em realizar uma "escuta sensível" ao que os professores e estudantes vêm realizando no cotidiano da escola, destacando as atividades bem-sucedidas, valorizando as boas práticas educativas e refletindo sobre as experiências que não se efetivam adequadamente, para ressignificar com eles, os sentidos de currículo, de projeto pedagógico, de educação e de escola.

O que se pretende é que o redimensionamento das práticas e a formulaçáo das proposiçóes ocorram de forma sintonizada com a realidade dos sujeitos do campo, ou seja, a partir do lugar dos sujeitos do campo, sem apartá-los do mundo global, do contexto urbano, com os quais, o território do campo interage continuamente, constituindo-se em sua identidade/subjetividade, a partir dessa interaçáo.

Todos sem exceção devem participar da produção dessas proposições, políticas e açôes: educandos, educadores, gestores, funcionários, pais, lideranças das comunidades, movimentos e organizações sociais locais; todos têm com o quê contribuir e devem, portanto, participar com suas ideias, críticas, sugestóes, ponderaçóes. Esse é um requisito fundamental e mesmo uma exigência para se democratizar o saber, as relaçóes sociais e o poder na escola, reconhecido inclusive pelas Diretrizes Operacionais para a Educação Básica das Escolas do Campo, quando estabelece que

[...] o projeto institucional das escolas do campo, garantirá a gestão democrática, constituindo mecanismos que possibilitem estabelecer relaçóes entre a escola, a comunidade local, os movimentos sociais, os órgãos normativos do sistema de ensino e os demais setores da sociedade. (CNE/CEB, 2002, Art.10) 
Outro passo importante para a transgressáo do paradigma seriado urbano de ensino se materializa quando, no cotidiano da sala de aula, valoriza-se a Inter-Multiculturalidade configuradora das identidades/subjetividades, dos modos de vida próprios e dos saberes das populaçóes do campo, ou seja, quando se reconhece a pluralidade de sujeitos e configuraçóes territoriais que se constituem a partir da diversidade cultural que caracteriza esses territórios.

A própria Secretaria de Educação Continuada, Alfabetização, Diversidade e Inclusão (Secadi), criada no interior do Ministério da Educação em 2004 (como Secad), onde se insere a Coordenação Geral da Educação do Campo, assumiu como meta pôr em prática uma política de educação que respeite e valorize o campo em sua diversidade, entendendo que o mesmo "engloba os espaços da floresta, da pecuária, das minas, da agricultura, dos pescadores, dos caiçaras, dos ribeirinhos e dos extrativistas, como espaço de inclusão social, a partir de uma nova visão de desenvolvimento". (SECAD, 2005)

No caso específico da Amazônia, onde nossos estudos sáo efetivados, a regiáo possui uma das mais ricas bio e sociodiversidade do planeta, formada por uma variedade de ecossistemas em que se combina a terra, o rio e a floresta como elementos que permeiam as formas tradicionais de trabalho e de reproduçáo da existência encontradas nos territórios do campo, a saber: a agricultura no trabalho com a terra, o extrativismo realizado na floresta, e a pesca nos rios, incluindo todas as suas expressóes materiais e simbólicas.

Essa diversidade se expressa também por meio de um conjunto de populaçóes que vivem no espaço urbano e rural, habitando um elevado número de comunidades rurais, pequenas e médias cidades e algumas poucas metrópoles, que, em sua maioria, possuem poucas condiçóes para atender às necessidades dessas populaçôes, ao apresentarem infraestrutura precária e não dispor de serviços essenciais básicos, sobretudo no campo. As pequenas comunidades rurais abrigam a grande maioria das escolas multisseriadas, denominadas em muitos casos, de escolas isoladas, em face das grandes distâncias existentes entre si e entre elas e a sede dos municípios.

Entre as populaçóes e grupos que habitam a Amazônia no campo e na cidade, encontram-se caboclos, ribeirinhos, pescadores, extrativistas, coletores, indígenas e remanescentes de quilombos, colonos, migrantes de outras regióes brasileiras (especialmente do nordeste e do centro-sul) e estrangeiros, agricultores familiares assentados, sem terra, sem teto, posseiros, garimpeiros, atingidos por barragens; e segmentos populares, incluindo idosos, deficientes, jovens, crianças, mulheres, negros, trabalhadores, entre outros.

Um dos estudos específicos que realizamos sobre as escolas do campo e sua localização por comunidades rurais, tomando como referência o Censo Escolar 
do Inep de 2011, revelou que as 8.583 escolas rurais de Educação Básica existentes na Amazônia paraense estavam assim distribuídas:

- 1.263 em assentamentos rurais;

- 329 em colônia agrícola;

- 13 em comunidade garimpeira;

- 177 em comunidade indígena;

- 12 em comunidade praiana;

- 271 em comunidade quilombola;

- 1.678 em comunidade ribeirinha;

- 114 localizadas em comunidades de ilhas;

- 364 em vilas e povoados náo ribeirinhos;

- 184 em distritos municipais;

- 62 em comunidade rural em fazenda;

- 1.303 em comunidade Vicinal/Ramais/Rodovias/Estradas;

- 2.813 em comunidades rurais não especificadas.

Essas particularidades, que evidenciam a complexidade que configura a diversidade sociocultural, educacional e territorial da Amazônia devem ser pautadas nas reflexóes e processos formativos a serem realizados com professores, gestores, estudantes, pais, lideranças comunitárias e dos movimentos sociais do campo, assim como no diálogo com pesquisadores, técnicos e dirigentes municipais e estaduais de educação, para que sejam inseridas em suas agendas políticas e educacionais, e com isso possam afirmar a diferença que se manifesta nos modos próprios de vida e existência das populaçóes e grupos que constituem a Amazônia.

Nesse processo, é importante considerar a conflitualidade existente nas relaçóes sociais que esses grupos e populaçôes estabelecem entre si, e apontar para uma convivialidade de forma pacífica, dialógica e emancipatória que precisa se efetivar entre esses grupos e populaçôes.

Essas referências, de forma explícita, se contrapõem e ajudam a minar as bases que fundamentam o paradigma seriado urbano de ensino, ao contribuir para ressaltar a heterogeneidade que configura a socioculturalidade do campo, fortalecendo, enquanto valores, a solidariedade, a alteridade, a justiça social, ajudando assim, a consolidar a igualdade na diferença, a unidade na diversidade.

As escolas do campo, que em sua grande maioria se organizam sob a multisseriação, são espaços marcados predominantemente pela heterogeneidade ao reunir grupos com diferenças de sexo, de idade, de interesses, de domínio de conhecimentos, de níveis de aproveitamento etc. Essa heterogeneidade inerente 
ao processo educativo que se efetiva na multissérie, na seriação ou em qualquer outra forma de organização do ensino, articulada às particularidades identitárias relacionadas a fatores geográficos, ambientais, produtivos, culturais etc; são elementos imprescindíveis na constituição das políticas e práticas educativas a serem elaboradas para a Amazônia e para o país.

Essa prerrogativa referencia e fortalece nossa intencionalidade de pensar a educação do lugar dos sujeitos do campo, tendo como horizonte a transgressáo do paradigma seriado urbano de ensino, pois se assumimos como proposição elaborar políticas e práticas educativas includentes e emancipatórias para as escolas do campo, é fundamental reconhecer e legitimar as diferenças existentes entre os sujeitos, entre os ecossistemas e entre os processos culturais, produtivos e ambientais construídos pelos seres humanos nos diversos espaços sociais em que se inserem, e não promover a homogeneização, a parametrização e o ranqueamento, conforme nos impóe a seriação.

Não obstante, não podemos desconsiderar a visão dos sujeitos envolvidos com as escolas rurais multisseriadas, que em grande medida consideram a heterogeneidade inerente ao ambiente escolar, como um fator que dificulta o trabalho pedagógico do professor, fundamentalmente porque no imaginário social se tem generalizado que as "classes homogêneas", entendidas muitas vezes como aquelas que reúnem estudantes da mesma idade na mesma série, são o parâmetro de melhor aproveitamento escolar e, consequentemente, de educaçáo de qualidade.

Contudo, os fundamentos teóricos que orientam nossos estudos apontam justamente o contrário, indicando ser a heterogeneidade um elemento potencializador da aprendizagem e enriquecedor do ambiente escolar, que poderia ser melhor aproveitado na experiência educativa que se efetiva nas escolas rurais multisseriadas, carecendo, no entanto, de mais estudos e investigaçóes sobre a organização do trabalho pedagógico, o planejamento e a construção do currículo, sintonizados com as peculiaridades de vida e de trabalho das populaçóes do campo, o que de forma nenhuma, em nosso entendimento, significa a perpetuação da experiência precarizada de educação que se efetiva nas escolas rurais multisseriadas tal qual refletimos nesse artigo.

Com todas essas reflexôes busca-se fortalecer a compreensão de que as mudanças a serem implementadas na atuação das escolas rurais multisseriadas envolvem, entre muitas outras questóes, a implementação de uma proposta de formação permanente dos professores que atuam nessas escolas. Formação essa que busque orientar suas atividades referenciadas pelas seguintes premissas: inter-relação entre os fatores macro e microssociais que envolvem as escolas do campo; afirmação dos parâmetros estabelecidos pela legislação educacional para assegurar o direito à educação dos sujeitos do campo; apropriação da produção 
teórica existente sobre educação rural e educação do campo; perspectiva interdisciplinar e dialógica entre os sujeitos e seus saberes culturais e científicos; e, reflexão crítica acerca das concepçóes de aprendizagem e das reflexões que têm sido produzidas sobre a seriação e seus impactos na organização do ensino e no trabalho docente.

\section{Referências}

BRASIL. Ministério da Educação. Secretaria de Educação Fundamental. Escola Plural: proposta político-pedagógica. Brasília: SEF, 1994.

. Presidência da República. Decreto n. 7.352, de 4 de Novembro de 2010. Dispóe sobre a Política de Educação do Campo e o Programa Nacional de Educação na Reforma Agrária - PRONERA.

. Presidência da República. Lei n. 12.960, de 27 de março de 2014. Altera a Lei no 9.394, de 20 de dezembro de 1996, que estabelece as diretrizes e bases da educação nacional, para fazer constar a exigência de manifestação de órgão normativo do sistema de ensino para o fechamento de escolas do campo, indígenas e quilombolas.

. Congresso Nacional. Lei no 13.005, de 25 de Junho de 2014. Aprova o Plano Nacional de Educação para decênio 2014-2023, e dá outras providencias. 2014. Disponível em: http://www2.camara.leg.br/legin/fed/lei/2014/lei-13005-25-junho-2014-778970-publicacaooriginal-144468-pl.html. Acesso em 20 Dez. 2014.

CNE/CEB. Diretrizes Operacionais para a Educação Básica nas Escolas do Campo. Resolução CNE/CEB n. 1, de 3 de Abril de 2002.

. Dias letivos para a aplicação da Pedagogia de Alternância nos Centros Familiares de Formação por Alternância (CEFFA). Parecer n. 1 em 15 de Março de 2006.

. Diretrizes Complementares para o atendimento da Educação Básica do Campo. Resolução CNE/CEB n. 2. Brasília-DF, de 28 de Abril de 2008.

- Notas para análise do momento atual da educação do campo. Seminário Nacional, Brasília, 15 a 17 agosto de 2012. (digitalizado)

FREITAS, L. C. de. Neotecnicismo e Formação do Educador. In: ALVES, N. (Org.). Formaçấo de Professores: pensar e fazer. São Paulo: Cortez. 2011. [Coleção Questôes da Nossa Época, v. 30].

GEPERUAZ. Classes Multisseriadas: desafios da educaçáo rural no Estado do Pará/ Regiáo Amazônica. Belém/PA, 2004. [Relatório de Pesquisa apresentado ao CNPq].

Currículo e Inovaçáo: transgredindo o paradigma multisseriado nas escolas do campo na Amazônia. Belém/ PA, 2007. [Relatório de Pesquisa apresentado ao CNPq].

Políticas de Nucleaçáo e Transporte Escolar: construindo indicadores de qualidade da educaçáo básica nas escolas do campo da Amazônia. Belém/PA, 2010. [Relatório de Pesquisa apresentado ao CNPq]. 
GEPERUAZ. Movimento Paraense por uma Educação do Campo e seus impactos na Escola Pública. Belém/PA, 2014. [Relatório de Pesquisa apresentado ao CNPq].

HAGE, S. M. et al. (Orgs.). Educação do Campo na Amazônia: retratos de realidades das escolas multisseriadas no Pará. 1. ed. Belém: M.M.Lima, 2005.

HAGE, S.; ANTUNES-ROCHA, M. I. (Orgs.). Escola de Direito: reinventando a Escola Multisseriada. Belo Horizonte: Autentica Editora, 2010.

INEP/MEC. Sinopse Estatística da Educação Básica: Censo Escolar 2002, 2010, 2011. IPEA/ MEC. Brasília. Disponível em http://portal.inep.gov.br/basica-censo-escolar-sinopse-sinopse.

CNEC. Por uma Política Pública de Educação do Campo. Texto Base da II Conferência Nacional por uma Educação do Campo. Luziânia/GO. 2004.

MINISTÉRIO DA EDUCAÇÃO. Portaria n. 86, de $1^{\circ}$ de Fevereiro de 2013. Institui o Programa Nacional de Educação do Campo - PRONACAMPO. DOU de 04.12.2013, no 24, Seção 1, p. 28.

MOLINA, M. C. Análises de Práticas contra-hegemônicas na formação de Educadores: reflexôes a partir do Curso de Licenciatura em Educação do Campo. In: SOUZA, J. V. (Org.). O método dialético na pesquisa em educação. Campinas: Autores Associados, 2014.

Recebido em 22 de dezembro de 2014.

Aprovado em 27 de fevereiro de 2015. 